\title{
Drought-tolerant cyanobacteria and mosses as biotechnological tools to attain land degradation neutrality
}

\author{
Alessandra Adessi ${ }^{1}$, Roberto De Philippis ${ }^{1}$, and Federico Rossi ${ }^{2}$ \\ ${ }^{1}$ Department of Agriculture, Food, Environment and Forestry - DAGRI, \\ University of Florence, via Maragliano 77, 50144 Florence, Italy \\ ${ }^{2}$ Department of Environmental Sciences, Informatics and Statistics (DAIS), \\ Cà Foscari University of Venice, Via Torino 155, 30172 Venezia Mestre, Italy \\ Correspondence: Alessandra Adessi (alessandra.adessi@unifi.it)
}

Received: 30 October 2020 - Revised: 29 January 2021 - Accepted: 10 March 2021 - Published: 13 April 2021

\begin{abstract}
The induction of biocrusts through inoculation-based techniques has gained increasing scientific attention in the last 2 decades due to its potential to address issues related to soil degradation and desertification. The technology has shown the most rapid advances in the use of biocrust organisms, particularly cyanobacteria and mosses, as inoculants and biocrust initiators. Cyanobacteria and mosses are poikilohydric organisms i.e., desiccation-tolerant organisms capable of reactivating their metabolism upon rehydration - that can settle on bare soils in abiotically stressing habitats, provided that selected species are used and an appropriate and customized protocol is applied. The success of inoculation of cyanobacteria and mosses depends on the inoculant's physiology, but also on the ability of the practitioner to identify and control, with appropriate technical approaches in each case study, those environmental factors that most influence the inoculant settlement and its ability to develop biocrusts.

This review illustrates the current knowledge and results of biocrust induction biotechnologies that use cyanobacteria or mosses as inoculants. At the same time, this review's purpose is to highlight the current technological gaps that hinder an efficient application of the technology in the field.
\end{abstract}

\section{Introduction}

Land degradation is a severe current issue to be monitored and managed worldwide (Mitri et al., 2019). Consequently, one of the main strategic objectives of UNCCD framework 2018-2030 is land degradation neutrality, i.e., a state in which the amount and the quality of land resources remain stable or increase within specific temporal and spatial scales and ecosystems. Such a goal requires implementing sustainable land management policies and the restoration of degraded and abandoned lands, including those affected by desertification and drought. Drylands are particularly subjected to soil loss and consequent desertification, the latter transforming croplands and rangelands into unproductive and, at best, carbon-neutral soils (Rossi et al., 2015).
Soil degradation has profound effects on the belowground microbial community. In the pedosphere, defined as the layer of the Earth composed of soil and where soil formation occurs, bacteria have a fundamental role in the maintenance of soil productivity and structure, owing to the large number of ecosystem processes that they contribute to and that govern ecosystem functioning (van der Heijden et al., 2008). They intervene in biogeochemical cycles and stabilize soil mineral clusters, which persist through mechanical disruption and wetting events (Wilpiszeski et al., 2019). Bastida et al. (2006) pointed out how soil degradation is consistent with a decrease in parameters related to soil microbiological quality, like soil urease and dehydrogenase activities, water-soluble carbon, water soluble carbohydrates contents, and respiration (Bastida et al., 2006). 
In arid and semiarid environments, $70 \%$ of the soil surface is colonized by peculiar communities called biocrusts, a mosaic of phototrophic microorganisms, fungi, heterotrophic bacteria, lichens, and bryophytes (Belnap and Lange, 2001; Maestre et al., 2011). Although long-neglected in restoration ecology (Bowker, 2007), biocrusts are of high importance for the maintenance of the steady state of ecosystems subjected to abiotic stresses. These microbiotic formations improve soil stability and reduce wind and water erosion (Mazor et al., 1996), increase soil temperature (Gold and Bliss, 1995), although not in all climates (Xiao et al., 2019), and control hydrological processes and water distribution (Adessi et al., 2018; Belnap, 2006; Cantón et al., 2014; Chamizo et al., 2016). In addition, their onset determines the accumulation of nutrients, gases, and water in the uppermost soil layers owing to the contribution of the biocrust primary producers, which fix significant amounts of $\mathrm{N}$ and $\mathrm{C}$ (Antoninka et al., 2020a; Pointing and Belnap, 2012). Being of primary ecological importance, biocrusts are considered a reliable index of soil health, while the loss of biocrusts can result in a significant downturn in environmental status and favor the increase in abiotic stress levels (Bowker, 2007).

Due to their ecological importance for the functioning of dryland ecosystems, biocrusts have been the subject of articles and technical papers dealing with the elaboration of sustainable strategies for their preservation and restoration when damaged by physical (e.g., erosion, trampling, grazing) and climate disturbance. Biocrust restoration has been targeted by restoration practitioners for two main reasons, clearly synthesized by Antoninka et al. (2020a): to reinstate lost ecosystem functions and increase biodiversity owing to the large variety of organisms for which biocrusts represent the foundation.

Several recent investigations elaborated reliable protocols to cultivate biocrusts, starting from biocrust material (Bethany et al., 2019; Chiquoine et al., 2016; Maestre et al., 2006; Velasco Ayuso et al., 2017, 2020); mixed or single biocrust organisms, notably cyanobacteria (Chamizo et al., 2018, 2019; Mugnai et al., 2018a; Nelson et al., 2020; Román et al., 2018, 2020a); and mosses (Bu et al., 2018; Slate et al., 2020). Cyanobacteria are pioneers of bare soils and are considered the first natural biocrust formers (Becerra-Absalón et al., 2019). They naturally provide most of the adhesion and cohesion in biocrusts thanks to the excretion of extracellular polymeric substances (EPS) that wind up soil particles and create macroaggregates (Aspiras et al., 1971; Falchini et al., 1996; Rossi et al., 2018). Their limited growth requirements and the possibility to grow exploiting sunlight as an energy source theoretically allow the obtainment of a high quantity of biomass to turn into inoculum for large experimental sites (Colica et al., 2014; Lan et al., 2015). Mosses are bryophytes, encountered in biocrust at later levels of development (LODs) (Belnap et al., 2008) and are important carbonstoring organisms that strongly contribute to soil fertility, provide soil stability (Danin and Ganor, 1991), and control of run-off yields (Bu et al., 2018; Xiao and Veste, 2017). It was observed that, though transient, they can be present as first colonizers in some specific settings, such as the conifer systems (Grover et al., 2020). In the field, cyanobacterial crusts (Fig. 1a), an incipient biocrust LOD, can acquire more complex features and multiple trophic levels, with possible colonization by mosses and/or lichens to become lichen crusts (Fig. 1b) or moss crusts (Fig. 1c), according to the dominant species (Li et al., 2013). Cyanobacteria and mosses are poikilohydric organisms, in that they can equilibrate with the relative air humidity during dry periods and then easily physiologically recover after hydration. This capability is found in cryptogamic organisms such as lichens, ferns, and vascular plants such as pteridophytes and lycophytes (Smith et al., 1997).

LOD shifts of biocrusts are consistent with changes in community composition, microbial activities, and species relations ( $\mathrm{Li}$ et al., 2016). In addition, the progression to moss or lichen crusts is consistent with modifications in soil physiochemical properties, particularly moisture level, $\mathrm{N}$ and C contents, stability (Chamizo et al., 2012), silt and clay contents, and soil porosity (Gao et al., 2014). Both lichens' and mosses' establishments contribute to the achievement of soil stability (Lan et al., 2014). The shift to moss and lichen crusts is favored or hampered by environmental conditions. For example, since mosses and lichens prefer moistened and shady spots, on windward and dry spots cyanobacterial crust is the most common observed biocrust LOD in natural environments. However, it needs to be stated that mosses are not always the last organisms to be recruited. As we will reiterate later, mosses such as Pottiaceae, Grimmiaceae, and Bryaceae may be responsible for the initial biocrust formation, owing to the stabilizing capability of rhizoids, and for subsequent vascular plant colonization (Zhao et al., 2009).

The induction of biocrusts by inoculating cyanobacteria or mosses is a technologically appealing eco-friendly approach that allows employing species that are native to the reclamation site and are already acclimated to local environmental conditions. These are the only two groups of biocrust organisms for which a restoration technology currently exists. Lichens, which are also relevant biocrust components, are very difficult to employ to produce inoculants due to the difficulty of massively cultivating them in the laboratory or the greenhouse. Only a few studies concerning lichen cultivation and inoculation have been reported, due to the challenging cultivation, inoculation, and growth-assistance strategies required (Zhou et al., 2020).

The induction of biocrust formation by inoculating selected species of poikilohydric phototrophs can target two possible goals: the restoration of damaged biocrusts or the induction of biocrusts ex novo. Being such organism ecosystem engineers in high-abiotic-stress systems, their establishment in biocrusts in environments affected by desertification can lead to the transition from a degraded ecosystem state to an ameliorated alternative steady state (Bowker, 2007). 

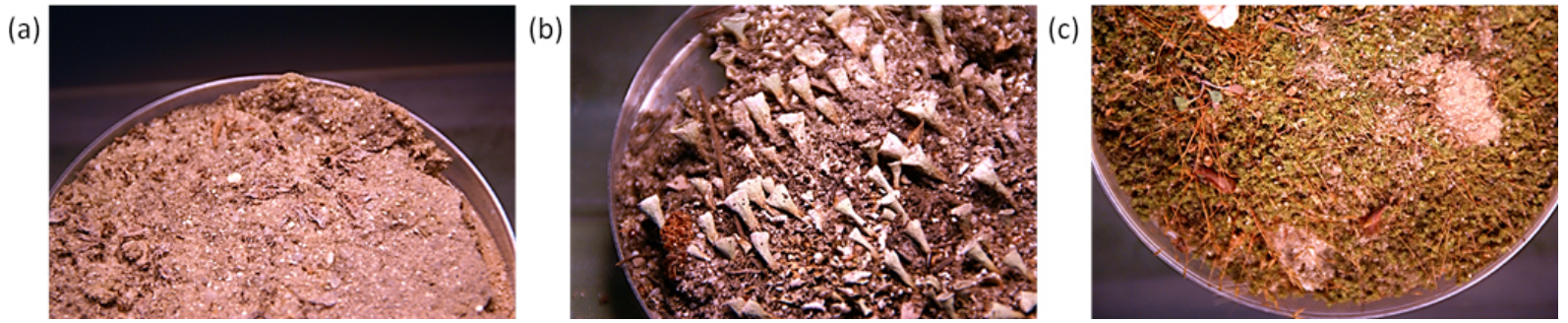

Figure 1. Natural biocrusts at different levels of development: (a) a cyanobacterial biocrust, (b) a lichen crust, and (c) a moss crust. Samples were collected in Mata Nacional da Machada, Lisboa. Picture and graphic elaboration by Alessandra Adessi.

The ex novo induction of biocrusts could also work by widespreading carbon sink areas and productive soil (Rossi et al., 2015; Zaady et al., 2010).

Several recent experiments, which are to be reviewed here, examined cyanobacteria and moss inoculation potential to induce biocrusts for environmental restoration purposes. Although some of them provided significant advances in the area of cultivation, we hereby discuss how several aspects concerning inoculum production and inoculum dispersion methodologies need to be investigated further to be able to bridge science and practice. Our aim is to review the biotechnological acquisitions and the critical points still to be solved for future scale-up from microcosm and mesocosm studies to successful field inoculation.

\section{Cyanobacteria inoculation}

Cyanobacteria inoculation (also termed cyanobacterization) is a technology that has been extensively investigated for its effects on soil fertility and plant growth. The use of cyanobacteria as a "green manure" in agriculture have been documented since the 1950s (e.g., Hamdi, 1982; de Mulé et al., 1999). Seeding with diazotrophic genera such as Nostoc, Anabaena, and Calothrix, alone or in combination, determined positive effects in a significant number of crops, with improvements concerning the number of productive tillings, plant height, panicle height, weight of yield and straw, harvest index, and grain index, among others (Ali, 2015).

Cyanobacterization to combat desertification is a more relatively recent investigation topic, dating back only a couple of decades. Recent studies have proven that, if the right strains are employed, and the inoculation process is successful, the effects in terms of soil fertilization and stabilization are quick and significant even when only cyanobacterial crusts are present (Chamizo et al., 2018, 2019; RonceroRamos et al., 2019a, b; Rossi et al., 2017). A successful inoculation determines the formation of cyanobacterial crusts, a first biocrust LOD.

\subsection{Cyanobacteria inoculation: critical issues}

Natural biocrust communities of arid soils are constituted by hundreds of species showing adaptation traits to local stresses (Belnap, 2003; Evans and Johansen, 1999). Selected isolates can be used as inocula, exploiting their adaptation to the environmental conditions of the reclamation site. When inoculated, isolates may exhibit both bioconditioning and biofertilizing capabilities or, more commonly, either one or the other (Maqubela et al., 2010). However, when isolates are reintroduced in their native soil, they may display a different capability to establish and produce significant inoculation effects (Rossi et al., 2017). To survive under high-abioticstress conditions after being dispersed in the soil, the inoculant must possess suitable physiological stress-tolerance traits and, in particular, the capability of constituting stable and erosion-resistant bio-aggregates. It is crucial to perform screenings at laboratory scale and under natural outdoor conditions to test the effects of drought, UV irradiation, and high saline concentration, which are typical of high-abiotic-stress environments. The tolerance to natural conditions can be improved by "hardening off", namely the subjecting of cyanobacterial candidates to preliminary preconditioning treatments consisting of several dry-wet cycles and progressive increase in illumination (Giraldo-Silva et al., 2019) before inoculating them in the field. Isolates may show either good, fair, or limited capability to form physically stable cyanobacterial biocrusts in short times. Indeed, a positive assessment of stress tolerance traits does not necessarily guarantee a biocrust-forming capability, which has to be separately assessed. For example, Nostoc spp. and Scytonema javanicum synthesize UV-screening pigments (Garcia-Pichel and Castenholz, 1991, 1993), are capable to easily recover from UV-related damages (Chen et al., 2013), and have drought and salt stress defensive mechanisms (Tamaru et al., 2005; Tang et al., 2007). However, these strains were far worse sand stabilizers of arid sandy soils than Microcoleus vaginatus, which does not possess any of these traits (Hu et al., 2002). The quick soil-stabilizing capability has relevance depending on the strength of the erosive forces in the site to reclaim (Park et al., 2015). In environments characterized by high wind speed and unconsolidated soil, biocrusts with a significant wind threshold friction velocity are able to en- 
dure and not be worn away. Some natural biocrust-dwelling non-heterocystous genera such as Microcoleus, Leptolyngbya, and Schizothrix are proficient sand stabilizers and have been proven to induce biocrusts with significant aggregate stability and tensile strength (Hu et al., 2002, 2012; Mugnai et al., 2018a, b). In particular, strains with the capability to glide in the substrate (e.g., M. vaginatus, Leptolyngbya ohadii) seem to have an advantage and more apt to determine the formation of stable and thick biocrusts (Mugnai et al., 2018b). The capability to migrate in the soil allows for adaptations to drought and intense light. For example, when topsoil is moistened, $M$. vaginatus glides to the soil surface, leaving its hygroscopic sheath behind, and then retracts in it when the soil dries and when the light is too strong (avoidance). The strain can also accommodate at the soil depths where light intensity is optimal ( $\mathrm{Hu}$ et al., 2003). Following these movements, sheath material is distributed in the soil, cementing soil particles (Belnap, 2003). On the other hand, non-gliding genera such as Tolypothrix spp., Nostoc spp., and Scytonema spp. are localized at the topsoil and synthesize sunscreen molecules to protect from UV radiation (Román et al., 2018). While being less valid sand stabilizers than M. vaginatus or Phormidium tenue (Hu et al., 2002), diazothrophic non-motile strains proved to be valid inoculants on substrates with a higher content in silt and clay where they exert a significant fertilizing effect (Chamizo et al., 2018; Román et al., 2018; Roncero-Ramos et al., 2019a, b). In order to attain both biostabilizing and biofertilizing effects, strains with a marked biofertilizing capability such as $S$. javanicum can be co-inoculated with strong biostabilizing strains such as $M$. vaginatus. The co-inoculation of $M$. vaginatus and S. javanicum (10:1) was successful in some large-scale studies conducted in Hopq Desert, China (Chen et al., 2006; Lan et al., 2014). S. javanicum greatly contributes to dinitrogenfixing activity and the maintenance of soil productivity (Deb et al., 2015).

Cyanobacterization studies generally report non-uniform protocols for inoculum preparation and dispersion (Nelson et al., 2020). Cyanobacterial inocula have consisted of wet or dry forms, with or without specific formulations (i.e., the addition of specific carriers and amendments). The biomass has been inoculated alone (no formulation) or mixed with sand, lime, gravel, or superabsorbent polymers or encapsulated in alginate or extruded soil pellets to enhance soil aggregation and prolong inoculum shelf life (Buttars et al., 1998; Park et al., 2015; Román et al., 2020a; Singh, 1961; Hamdi, 1982). Overall, there is a lack of exhaustive investigations examining how differences in the methodological approach can affect inoculation cyanobacterial survival and biocrust formation. Cyanobacteria can respond differently to inoculum preparation treatments, such as the desiccation process associated with pelletization (Román et al., 2020a). As an example, in microcosms, we observed how M. vaginatus develops biocrusts if inoculated as liquid biomass, while the same powdered inoculum did not produce significant aggre-

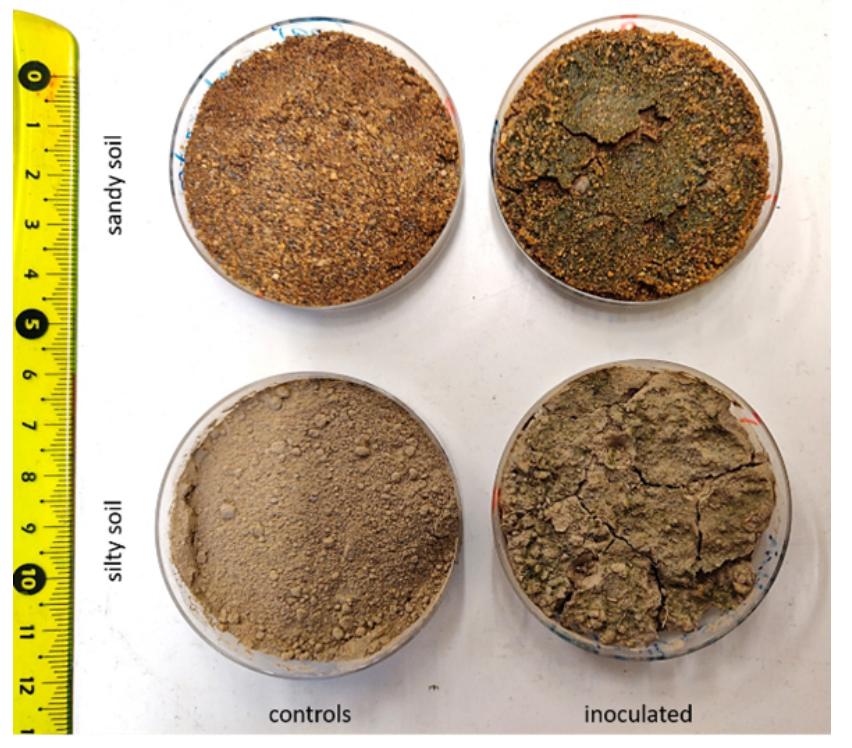

Figure 2. Schizothrix delicatissima AMPL0116 biocrusts induced on sandy soil and silty soil microcosms, inoculated and incubated according to Mugnai et al. (2018a). The strain is not motile and biocrust development is mainly superficial, especially on sandy soil. Picture by Alessandra Adessi and Federico Rossi at DAGRI, University of Florence.

gation even though followed by watering (our unpublished data). Although further study is needed to provide valid explanations, the reason could be related to the different physiological responses to the biomass treatment to remove water. It is possible that a forced drying process does not allow the drought-response systems - presumably EPS synthesis, compatible solute accumulation, down-regulation of photosynthesis, N fixation, RNA polymerase, and other processes (Singh, 2018) - to be fully activated, hence affecting cell viability after rehydration once inoculated. The level of homogeneity of biomass dispersion is another factor that can affect the development of the biocrusts. In microcosm it has been demonstrated that $L$. ohadii produced biocrusts with the highest consistency and stability when the inoculum was distributed as homogenously as possible over an entire available surface of the microcosm (Mugnai et al., 2020). A further parameter of importance is the optimal inoculum concentration, which has to be experimentally determined according to the strain physiology but also in relation to substrate characteristics. We have observed how the larger the grain size of the substrate, the higher the amount of inoculum per square centimeter needed to obtain cyanobacterial biocrusts with significant hydraulic and tensile strength (Mugnai et al., 2020). Figure 2 shows biocrusts induced in sand microcosm by inoculating Schizothrix delicatissima AMPL0116, with a typical morphology deriving from a topsoil-dwelling inoculant, characterized by cracks and curls on the surface (Fig. 2). 


\subsection{Field inoculation experiments}

The inoculation at a large field scale requires elaboration of cost-effective methodologies to cultivate large volumes of culture. In most case studies, biomass was produced using conventional culturing systems characterized by stepwise culture vessel volume increments (Guedes et al., 2013). However, classical methods are inherently expensive owing to the need of producing large volumes of culture medium and may not fit bundle-forming cyanobacteria that form clumps and have their growth hindered. In order to reduce implementation costs, the elaboration of cheaper culture media and suitable bioreactor designs should be pursued. For example, Roncero-Ramos et al. (2019a, b) demonstrated the possibility of growing Nostoc commune in a medium made with fertilizers detecting no negative impacts on inoculation effects. The use of circular open mixing raceway ponds (Liffman and Paterson, 2013), allowing the exploitation of direct sunlight, has been used to grow cyanobacterial biomass for large-scale cyanobacterization in Inner Mongolia, China (Rossi et al., 2017). The inoculum, initially placed into smaller $(1 \mathrm{~m} \times 4 \mathrm{~m})$ raceway ponds, is then transferred to larger ponds $(6 \mathrm{~m} \times 40 \mathrm{~m})$. The ponds are filled with nitrogen-free culture medium and stirred with one or more electrically driven paddle wheels (Zhou et al., 2020). This system easily applies to mixed cultures, being characterized by non-sterile conditions. On the other hand, it imposes a control for contamination. Lan et al. (2015) demonstrated that controlling temperatures and illumination regimes can limit contamination and be beneficial to cyanobacterial growth. It was found that temperatures below $30^{\circ} \mathrm{C}$ and light intensity between 600 and $700 \mu \mathrm{E} \mathrm{m}^{-2} \mathrm{~s}^{-1}$ (Liu, 2013) were the best conditions to restrain contamination by microalgae or protozoans.

Giraldo-Silva et al. (2019) solved the problem of bundle formations and consequent growth inhibition of cyanobacteria by successfully inoculating Microcoleus sp. on sterile cellulose tissue floating in growth medium in large petri dishes. The dried cellulose tissue was later shredded to harvest the biomass. This inoculum preparation and production was further improved by the application of a flexible fog-based irrigation system (Nelson et al., 2020).

Another essential step to optimize is the elaboration of a valid inoculum dispersion methodology. Ground dispersal approach using tank truck-mounted sprayers has been used to inoculate a mixed culture of $M$. vaginatus and S. javanicum on sand dunes of an experimental area in the Hopq Desert, China (Colica et al., 2014). However, this approach hampers a uniform distribution of the biomass owing to landscape natural unevenness and is invasive for the existing flora and microflora owing to the necessity to move dispersal equipment. The possibility of seeding from aircraft dispersal has been hypothesized (Sears and Prithiviraj, 2012), and one related patent already exists (Sears, 2012).

\section{Moss inoculation}

Mosses are biocrust components that have been receiving scientific attention as possible inoculants. In later biocrust LODs, under favorable site conditions (Bu et al., 2015), mosses are important carbon-storing organisms that are instrumental in increasing soil fertility, soil stability, and control run-off yields (Bu et al., 2018; Xiao and Veste, 2017). $\mathrm{Bu}$ et al. (2018) observed how biocrust mosses in the Chinese Loess plateau determined more than a $30 \%$ decrease in run-off yields and a more than $80 \%$ decrease in sediment yield compared to bare soil (Bu et al., 2018). Owing to their common association with cyanobacteria, moss inoculation can determine significant increases in soil $\mathrm{C}$ and $\mathrm{N}$ contents (Condon and Pyke, 2016). In addition, the establishment of moss biocrusts determines higher water adsorption rates at the soil surface and consequently a higher water infiltration than the other types of biocrusts. According to one report, desiccation-tolerant mosses can adsorb water up to $1400 \%$ of their dry mass (Michel et al., 2013). This feature can contribute to lowering the stress in arid environments deriving from water scarcity, a factor that hinders land recovery. The presence of mosses is also considered facilitative to plant establishment in some arid ecosystems (Zhao et al., 2009).

While the majority of moss species prefer humid environments, Condon and Pyke remarked how the presence of mosses characterizes not only humid environments, but also the early stages of primary succession in other climates worldwide (Condon and Pyke, 2016). Members of the families Pottiacea, Grimmiacea, and Bryaceae are able to grow well on sand dunes, probably owing to their capability of building dense belowground aggregates of stems which work as valid sand-stabilizing agents (Zhao et al., 2009). The growth of mosses on unstable and sandy substrates has a significant positive impact of soil stabilization and reduction of erosion. Mosses determine the formation of erosionresistant soil aggregates by enmeshing soil particles in moss rhizines (Belnap, 2013) to the point that they can stabilize the soil to a higher degree than cyanobacteria (Belnap and Gillette, 1998). Furthermore, mosses bring an additional aesthetic value in restoration, that is particularly appealing when restoring sites within or nearby anthropic environments.

The inoculation of mosses could be a valid rehabilitation approach, especially in cold deserts and steppes, where mosses could find suitable environmental conditions and grow to dominate the substrate (Antoninka et al., 2016). The off-site cultivation of moss species represents a valid approach to produce inoculum. The successful cultivation of common biocrust-colonizing mosses, such as Syntrichia caninervis and Syntrichia ruralis in North American deserts (Hilty et al., 2004), would be highly desirable to set up restoration approaches in disturbed sites.

An aspect that facilitates the use of mosses as inoculum is that they can grow vegetatively from small fragments from any part of the plant (Stark et al., 2004). Since moss natu- 
rally propagates by the dispersion of stems and leaves, moss inoculation has often been conducted using fragments as the actual inoculum. It has to be stressed, however, that some species such as Bryum arcticum and Didymodon vinealis have been shown to grow better starting from ground moss material than from spores of fragments (Xiao et al., 2011; Zhou et al., 2020). Due to their poikilohydric nature, dried fragments may be stored for a long time before being inoculated, without loss of viability. In this regard, the research is making steps forward, observing that long-term conservation of propagules is not possible for all the species. For example, Guo et al. (2020) observed a relatively well-maintained vegetative regeneration capability of Didymodon tectorum after $127 \mathrm{~d}$ of storage; Barbula unguiculata lost nearly $96 \%$ of gametophyte vigor index after the same period. At the same time, cells of $S$. ruralis, withstanding long dormancy, can be stored even for 20 years in an herbarium (Doherty et al., 2020).

Condon and Pyke suggested the use of the fragments where apical leaves remain green at the time of desiccation (young leaves), as they have a higher recolonization capability (Condon and Pyke, 2016). They also suggested hydrating propagules for $20 \mathrm{~min}$ before inoculation, in order to inoculate actively photosynthesizing moss fragments which are more tolerant to inoculation stress. Bu et al. $(2015,2018)$ dried the mosses at $35^{\circ} \mathrm{C}$ and then ground moss stems and leaves with a plant grinder before hand-sowing moss fragments uniformly. The reference amount of inoculum has been expressed as absolute propagule weight $(2.48 \mathrm{~g})(\mathrm{Bu}$ et al., 2015) or as propagule concentration $\left(700 \mathrm{~g} \mathrm{~m}^{-2}\right)$ (Bu et al., 2018). Condon and Pyke hydrated $1 \mathrm{~g}$ moss fragments and then spread them over the field at a concentration of $43.5 \mathrm{~g}$ (mosses) $\mathrm{m}^{-2}$ (Condon and Pyke, 2016). Antoninka et al. (2016) inoculated suspensions of $S$. caninervis and $S$. ruralis in volumes of $5 \mathrm{~mL}$ in $16 \mathrm{~cm}$ diameter plastic containers. Bu et al. (2018) inoculated propagules in outdoor mesocosms by distributing them dry as a slurry made of wood fiber $\left(100 \mathrm{~g} \mathrm{~m}^{-2}\right)$, binder $\left(3 \mathrm{~g} \mathrm{~m}^{-2}\right)$, and water $\left(4.2 \mathrm{~L} \mathrm{~m}^{-2}\right)$ by a spray-inoculation method (Bu et al., 2018).

\section{Moss inoculation: critical issues}

Since natural outdoor conditions can be recreated in the lab only to some extent, further multifactorial experiments are needed to define the optimal culture conditions for obtaining the maximum moss yields under natural conditions. Mosses are very sensitive to disturbance, which can cause change in their coverage, composition, and function (Bu et al., 2015). Therefore, moss inoculation can be challenging in highly disturbed areas where crusts are at early-stage LODs, while representing a valid approach to restore biocrusts at more mature LODs. A lot of abiotic factors can impinge on moss establishment and growth, including the annual rainfall amount, soil $\mathrm{pH}$, soil calcium carbonate content, plant cover, texture, soil organic carbon, and soil texture (Zhao et al., 2009). These factors affect moss establishment according to moss ecotypes and their phenotypic adaptation to the abiotic stresses of their native environment. In general, it has been observed that the scarcity of nutrients and temperature are other significant limiting factors to moss growth. The high sensitivity of mosses to environmental conditions accounts for the limited amount of moss cultivations successfully transferred to the field in China (Zhou et al., 2020). The wide array of parameters affecting moss growth implies the necessity to elaborate species-specific "recipes" for cultivation, considering the single and most significant constraints. The modulation of resource availability and hydration have been investigated in a number of studies. Bu et al. (2018) tested the addition of Hoagland's solution (whose complete formula can be found in Bever et al., 2012) as resource compensation $\left(2.1 \mathrm{~L} \mathrm{~m}^{-2}\right)$ and found significant positive improvements in moss density in a field plot experiment. This confirms that macronutrients such as $\mathrm{K}, \mathrm{P}$, and $\mathrm{Ca}$, also contained in Hoagland's solution, benefit moss growth (Bowker et al., 2005). The study of the best nutrient formulation is fundamental to determine the most beneficial effects on a specific moss species. An example study is represented by that of Yang et al. (2019). This research group tested the effects of different types of nutrient solutions, namely Knop's solution, Murashige-Skoog (MS), Benecke, Part and Hoagland's solution, glucose and sucrose, and the plant growth regulators thidiazuron, 6-benzylaminopurine, and naphthaleneacetic acid on biocrusts dominated by $D$. vinealis, native to the Chinese Loess plateau. They observed how Knop's solution, MS, Benecke, and Part and Hoagland's nutrient solutions improved the coverage and plant density of moss crusts, although to different degrees, with Hoagland's nutrient solution being the most effective nutrient amendment. At the same time, they observed a concentration-related inhibitory effect of the thidiazuron and of glucose and sucrose; the addition of 6-benzylaminopurine was ineffective as was the naphthalacetic acid. Finally, they came down to an optimal nutrient medium constituted by Hoagland's solution, low glucose and sucrose concentration (lower than $10 \mathrm{~g} \mathrm{~L}^{-1}$ ), and small concentrations of plant regulators (i.e., smaller than $1 \mathrm{mg} \mathrm{L}^{-1}$ ). Antoninka et al. (2016) also found that fertilization with Knop's solution $\left(\mathrm{Ca}\left[\mathrm{NO}_{3}\right]_{2}, \mathrm{KNO}_{3}, \mathrm{MgSO}_{4}\right.$, $\mathrm{KH}_{2} \mathrm{PO}_{4}, \mathrm{ZnSO}_{4}$ ) every 2 weeks was beneficial to the growth of $S$. caninervis and S. ruralis in North American drylands. Similar beneficial effects of the use of Knop's solution were obtained with Bryum pallescens, B. recurvulum, B. argenteum, and B. unguiculata in China (Zhou et al., 2020).

The optimal growth temperature for moss growth ranges quite widely between 5 and $25^{\circ} \mathrm{C}$ according to the species and the biome of origin (Duckett et al., 2004). The optimal growth temperature may depend on the climate of origin. The optimal temperature for tropical taxa ranges between 20 and $25^{\circ} \mathrm{C}$, while it may range between 10 and 15 or even 5 and $10^{\circ} \mathrm{C}$ for species from cooler climates; temperatures above $30^{\circ} \mathrm{C}$ even for short periods can be fatal or 
at best highly damaging to most taxa (Duckett et al., 2004). $B$. argenteum-dominated biocrusts collected from $\mathrm{Mu}$ Us Sandland, China, were grown at the optimal temperature of $15^{\circ} \mathrm{C}$ (Bu et al., 2015). Incubation temperature can be tricky, as temperatures slightly outside the optimal value might determine the inhibition of growth. For example, the growth of Barbula vinealis was inhibited above $17^{\circ} \mathrm{C}$. However, different growth temperatures may differentially affect the net photosynthetic capacity and temperature relations. For instance, one study supported the inverse relationship between photosynthetic rates and latitude for Polytrichum commune collected in sites near Utqiagivik and Fairbanks, Alaska; Schefferville and Mont Saint-Hilaire, Canada; and Gainesville, Florida (Sveinbjörnsson and Oechel, 1983). Moreover, it was observed how B. argenteum var. muticum Brid., part of continental Antarctica plant life, could withstand full sunlight without being affected by UVA or UVB (Schroeter et al., 2012), apparently not by shoot acclimation but by the production of new shoots and a constant capability of maintaining photosystem health. This contrasts with more temperate climates, where high light is typically avoided by desiccation.

Indeed, illumination is another paramount factor that has to be controlled. In laboratory settings irradiance is often suboptimal compared to the field, where it reaches values of $500-700 \mathrm{~W} \mathrm{~m}^{-2}$ in full sun, except for mosses growing in the shade (Duckett et al., 2004). High light and continuous illumination are therefore advised. This has been corroborated by $\mathrm{Bu}$ et al. (2015), who demonstrated that low light intensity determined low productivity of EPS and low chlorophyll $a$ contents of cultivated moss biocrusts, while $12000 \mathrm{~lx}$ illumination determined the highest peak of these values. However, this cannot be considered a general rule as, in nature, shaded locations generally determine higher moss yields compared to those that are exposed (Bu et al., 2018; Lan et al., 2014), and in at least one case, like those of $S$. caninervis, it was demonstrated that light intensity had no impact on the growth (Xu et al., 2008). Due to the biological and physiological differences among bryophyte species and to the adaptation of bryophyte species to their native habitat, the light intensity has to be optimized in each case study.

As previously stated, hydration is a key factor for moss establishment. The optimal amount of water to provide to the inoculum before and after dispersion has to be clearly determined. To avoid vitality loss, moss fragments must receive enough water to photosynthesize and fix enough carbon to balance carbon lost with respiration (Stark et al., 2011). Consequently, hydration must assure an optimal photosynthetic activity. To assure this, as already reported in this review, for example, Condon and Pyke hydrated fragments of B. argenteum and S. caninervis for $20 \mathrm{~min}$ prior to fragment dispersion in the field, disregarding the continuous water provision which was guaranteed in the field (Condon and Pyke, 2016). Mosses' tolerance to desiccation can depend on inherent species-specific capabilities or on phenotypic plastic- ity, which is also responsible for thermal tolerance observed between different ecotypes (He et al., 2016). The factors impinging on desiccation tolerance are the rate of desiccation, the equilibrating water content, and the duration of desiccation, in which moss tissues remain dehydrated. Studies on moss desiccation capability focus both on induced desiccation tolerance, which is characterized by a slow desiccation rate that prepares the tissues for the next drying event, and on the hardening process, which prepares the moss structure to sustain a dehydration event at any speed (Brinda et al., 2016). Hardening has been demonstrated for bryophyte gametophytes with three possible methods: a slow dehydration followed by a rapid dehydration, the treatment with abscisic acid followed by a rapid dehydration, and a partial dehydration followed by a rapid dehydration (Brinda et al., 2016).

Studies such as that of Greenwood et al. (2019) are essential to study the physiological response to desiccation between different ecotypes of the same species. The authors observed a different inherent desiccation tolerance between different $B$. argenteum ecotypes and a different phenotypic plasticity, especially in the protonemal and juvenile shoot phases. These types of studies pave the way for possibly predicting reaction to climate change of moss inoculants and to set up valid hardening protocols. The large distribution of a species like $B$. argenteum also depends on genetic variability, which seems constitutive of such species (Pisa et al., 2013).

\section{Biocrust induction over a large scale}

\subsection{Inoculation with cyanobacteria}

Large-scale inoculation treatment with cyanobacteria is still quite limited, although some published results showed premises. Cyanobacteria represent the only inoculants that have allowed rehabilitation in 200 ha areas (Zhou et al., 2020). Noticeably, the experiments carried out by the Institute of Hydrobiology (IHB), Chinese Academy of Sciences, Wuhan, China, were carried out in five different deserts, i.e., Qubqi, Ulan Buh, Mu Us deserts, Horqin Sand Land, and the Hulun Buir Sand Land, covering an area of $40 \mathrm{~km}^{2}$ (Fattahi et al., 2020). When inoculating only M. vaginatus, cyanobacterial crusts were visible after $20 \mathrm{~d}$ from the inoculation (Chen et al., 2006). The mixed inoculum of M. vaginatus-S. javanicum $(10: 1)$ on sand dunes produced cyanobacterial crusts visible in only 1 week (Lan et al., 2014); a well-developed cyanobacterial crust had formed a few years after the inoculation with the mixed cyanobacterial suspension (Colica et al., 2014; Wu et al., 2013). Induced biocrusts in the Qubqi desert were visible well after 13 years following the inoculation (Fig. 3). Moreover, Wu et al. (2013) observed a darkening process on the soil surface over 7 years caused by increased pigment contents, mainly chlorophyll $a$ and scytonemin. Follow-up studies after large-scale inoculation with cyanobacteria evidenced how the induced biocrust system is characterized by the presence of biocrusts at later LODs 

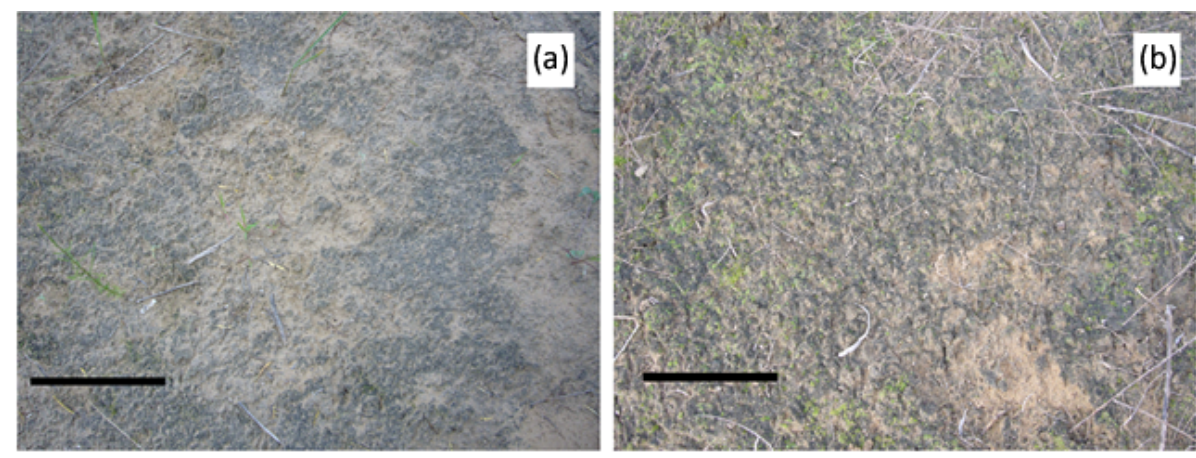

Figure 3. The 13-year-old induced biocrusts in the field in the Qubqi desert (Inner Mongolia), China, by inoculating liquid biomass of M. vaginatus and S. javanicum $(10: 1)$. (a) "Dark" biocrusts dominated by cyanobacteria (scale bar $=30 \mathrm{~cm})$ and (b) biocrusts with perfused moss colonization (scale bar $=10 \mathrm{~cm}$ ). Picture by Federico Rossi.

(moss/lichen crusts) surrounded by early LOD biocrusts (cyanobacterial biocrusts) in a mosaic arrangement (Li et al., 2013). The reason for such heterogeneity is not entirely clear. Still, it seems to follow resource distribution in the soil and seems to be the result of an equilibrium with environmental stresses that prevents any LOD shift of the "poorer" biocrust patches (Li et al., 2016).

Moss crusts generally show improved catabolic rates and bring an alteration of microhabitats at the topsoil that establishes a vertical gradient for soil microbes and changes the niche overlap (Li et al., 2016). It has been observed that phototrophs drive the biodiversity of bacteria and fungi during biocrust development (Maier et al., 2018). Also, vascular plants can be more represented following biocrust onset, as different species naturally establish thanks to the improvement of soil stability and nutritional conditions (Colica et al., 2014; Lan et al., 2014; Wang et al., 2009; Zhao et al., 2014). It was observed how EPS content is higher at the topsoil after cyanobacterial inoculation compared to non-inoculated sand and soil (Colica et al., 2014). This is indicative of the higher availability of carbon sources readily accessible to the heterotrophic crust microflora (Chen et al., 2014; Mager and Thomas, 2010). Biocrust age and LOD are parameters that showed consistency with an increase in soil and sand enzymatic activity, moving from cyanobacterial crusts to lichen crusts (Miralles et al., 2012). Two classes of enzymes, hydrolase and sucrase, involved in the degradation of carbohydrates, are mainly directed to the more soluble smaller EPS fractions, which are thus readily utilizable by the heterotrophic microflora (Chen et al., 2014). The soil and sand EPS content is also consistent with an increase in water storage against evaporation and the quantity of water captured from non-rainfall sources (e.g., plant guttation, water vapor) (Adessi et al., 2018; Colica et al., 2014).

\subsection{Inoculation with mosses}

As opposed to optimal laboratory settings, under natural conditions it is impossible to control abiotic parameters; hence this may hinder moss growth, even after an initial establishment (Zhou et al., 2020). Therefore, inoculation in the field currently has the primary need of successful inoculation methodologies, evidencing and controlling the factors involved in moss establishment.

Some inoculation experiments in the field conducted in China using $S$. caninervis, B. argenteum, B. articum, and $D$. vinealis have been successful. However, it appears that one of the major constraints to large-scale inoculation for experimentalists is the actual low cultivation yields achieved in laboratories and greenhouses. The consequent low availability of inoculum sources has so far restricted the scale of outdoor moss application only to small plots $\left(0.5 \mathrm{~m}^{2}\right)$ (Zhou et al., 2020). At the same time, the inoculation of field-collected moss biocrusts has the drawback of needing the retrieval of intact biocrusts from close sacrificial areas, putting healthy areas at risk.

So far, both field inoculation studies conducted in China and in the Great Basin, USA, have enlightened the need to control watering, shade, and nutrient availability to attain moss establishment and growth in the field (Condon and Pyke, 2016; Zhou et al., 2020). For example, in China the maximal growth of $B$. argenteum to 70 stems per square centimeter was obtained in a 4-month period, by controlling nutrient availability, shade, and water provision (Bu et al., 2018). Similarly, Yang (2016) cultivated B. argenteum by inoculating propagules at a concentration of $500 \mathrm{~g} \mathrm{~m}^{-2}$ and watering at a rate of $3 \mathrm{~L} \mathrm{~m}^{-2}$ every $2 \mathrm{~d}$ until it reached a coverage of $70 \%$ in $75 \mathrm{~d}$ (Yang, 2016). The application of a jute net, commonly used for erosion control, resulted functionally to increase water retention at the soil surface and sustain moss growth. The beneficial effects of the jute net probably also extend to lower soil temperature and exposure of mosses, keeping them more firmly in place (Condon and Pyke, 2016), increasing soil microtopography, and reducing wind and water erosion (Slate et al., 2020). 


\section{Habitat treatments}

According to Bowker, a restoration is achieved only by addressing the highest stress barrier of the ecosystem to restore (Bowker, 2007). Hence, the odds of inoculation success strongly depend on tailored side actions to restoration aiming at soil stabilization if soils are actively eroding and/or addressing existing habitat deficiencies.

In general, needed interventions are mainly directed to lower stress barriers typical of drylands, as water scarcity (Maestre et al., 2006), nutrient scarcity, and/or accelerated erosion rates (Young et al., 2019). However, the restoration approach must also be driven by the general context of climate and the severity of the disturbances afflicting the reclamation site, as that can impinge on whether or not it is easy for biocrusts to establish (Antoninka et al., 2020a, b).

According to the type of soil and abiotic environmental conditions, artificial soil stabilization (AS) strategies may be applied since it has been proven that biocrust development is strongly entailed in soil micro-geomorphology ( $\mathrm{Li}$ et al., 2010). A combination of straw checkerboards and stabilizing plants such as the genus Salix was beneficial to biocrust development, both protecting from wind erosion and providing shade and improved microclimate conditions (Liu, 2013; Wu et al., 2013; Xu et al., 2008). The artificial increase in surface roughness can reduce wind erosivity and determine the formation of protected microsites (Li et al., 2010; Zhao et al., 2016).

Natural-fiber nets were applied to cyanobacteriainoculated sites (Román et al., 2020b) and to mossinoculated sites (Condon and Pyke, 2016) in order to assist initial inoculum acclimation and beginning of growth on site. Other soil-stabilizing and habitat-amelioration strategies have also been tested with fluctuating results: soil-stabilizing chemicals such as polyacrylamides were shown to be effective in both laboratory (Park et al., 2015) and field settings (Park et al., 2017) but were not as successful in other field experiments (Chandler et al., 2019). Psyllium, a mucilaginous compound extracted from the seed coat of Plantago insularis, showed amelioration of soil conditions more than promotion of biocrust development (Fick et al., 2019, 2020). $\mathrm{NaCl}$ addition allowed some initial soil stabilization due to physical crust formation without disturbing the biocrust growth, while gypsum was shown to not be suitable for cyanobacterial growth (Chandler et al., 2019). AS can be used in combination with other substances for inoculation, or as sole rehabilitation approach. AS alone can naturally favor biocrust development or recovery, although the methodology needs significant economic incentives and takes a long time to show effects (Bowker, 2007). It may often be useful to combine multiple AS strategies to observe successful biocrust development over time (Antoninka et al., 2020a, b). What in any case must be taken into account is the very high specificity of the reclamation site in terms of local soil and disturbance characteristics and geomorphology; each site may require customized AS strategies, which therefore need to be tested site by site (Faist et al., 2020).

With water being a limiting factor and considering the high evapotranspiration of many marginal soils, watering is needed, especially during the first days after inoculation, both concerning cyanobacteria and moss inoculation (Zhou et al., 2020). This can be an economical and practical burden, especially for isolated sites far from any facility or water reservoir, where water must be transported for long tracts. In this frame, it is worth mentioning that some cyanobacterial strains such as $L$. ohadii and $S$. delicatissima have shown rapid biocrust formation capabilities even with water provisions comparable to desert dewfall amounts (Mugnai et al., 2018b), thus being promising for the application in hyperarid settings. However, such strains have only been tested at laboratory scale, while field tests still need to be conducted.

\section{Conclusions}

The use of cyanobacteria and mosses as inoculants to induce biocrusts has shown great premises so far to reclaim marginal soils. The level of development of these two biotechnologies is currently at different stages, with cyanobacteria inoculation in large areas having been studied and attempted for longer compared to the moss-inoculation studies specifically aimed at land degradation neutrality. Present efforts must be directed to fill the existing gaps in the technology. These mainly relate to the following.

- More knowledge of the mechanisms at the basis of a successful cyanobacterial crust induction with cyanobacteria and a more in-depth understanding of the primary factors (biotic and abiotic) controlling the odds of inoculation success are needed. Regarding mosses, further study must be directed to optimize inoculation methodology, improving with natural or artificial methods. Further multifactorial experiments are needed concerning both cyanobacterial and moss inoculants to improve their applicability in the field.

- More standardized and shared screening procedures for cyanobacterial and moss isolates are needed to facilitate the flow of information and fair data comparison among scholars.

- In the inoculum production phase, there is the need to elaborate on new cost-effective culturing systems for cyanobacteria and mosses. There is a need for protocols directed to facilitate the growth of clump-forming filamentous strains such as Microcoleus spp. (GiraldoSilva et al., 2019) using economically sustainable culturing systems allowing the restriction of contamination in the case of cyanobacteria. In the case of mosses, new strategies must be set up to increase inoculum production yields to use in the field, avoiding the use of sacrificial natural biocrusts. Studies must also be directed 
in improving moss propagule storage, evidencing those species whose inoculant can be stored for longer times without losing the regenerative capacity.

- Clear and agreed-upon procedures to grade the biocrust formation capability of moss and cyanobacteria inoculants must be determined. Approaches to assess biocrust physical stability should be applied to enrich and complement indirect measurements of biocrust development such as moss coverage (for moss inoculants) and chlorophyll $a$ abundance (mainly used for cyanobacterial inoculants).

- The possible integration with AS strategies, and multiple combinations, must be evaluated on a site-by-site basis.

Data availability. No data sets were used in this article.

Author contributions. All authors conceived the paper. AA and FR collected and analyzed the bibliography and drafted and revised the manuscript. RDP improved manuscript editing and contributed with constructive comments to the manuscript.

Competing interests. The authors declare that they have no conflict of interest.

Special issue statement. This article is part of the special issue "Biological soil crusts". It is not associated with a conference.

Acknowledgements. The authors would like to acknowledge Ricardo Carvalho for contributing to sample collection (Fig. 1) and Jalil Kakeh and Sonia Chamizo for providing the samples pictured in Fig. 2.

Review statement. This paper was edited by Laura ConcostrinaZubiri and reviewed by three anonymous referees.

\section{References}

Adessi, A., Cruz de Carvalho, R., De Philippis, R., Branquinho, C., and Marques da Silva, J.: Microbial extracellular polymeric substances improve water retention in dryland biological soil crusts, Soil Biol. Biochem., 116, 67-69, 2018.

Ali, A. S.: Response of rice plants to inoculation with indigenous strains of cyanobacteria along with different levels of $\mathrm{N}$ fertilizers, Adv. Biochem. Biotechnol., 1, 1-14, 2015.

Antoninka, A., Bowker, M. A., Reed, S. C., and Doherty, K.: Production of greenhouse-grown biocrust mosses and associated cyanobacteria to rehabilitate dryland soil function, Restor. Ecol., 24, 324-335, https://doi.org/10.1111/rec.12311, 2016.
Antoninka, A., Faist, A., Rodriguez-Caballero, E., Young, K. E., Chaudhary, V. B., Condon, L. A., and Pyke, D. A.: Biological soil crusts in ecological restoration: emerging research and perspectives, Restor. Ecol., 28, S3-S8, https://doi.org/10.1111/rec.13201, 2020a.

Antoninka, A., Bowker, M. A., Barger, N. N., Belnap, J., GiraldoSilva, A., Reed, S. C., Garcia-Pichel, F., and Duniway, M. C.: Addressing barriers to improve biocrust colonization and establishment in dryland restoration, Restor. Ecol., 28, S150-S159, 2020 b.

Aspiras, R. B., Allen, O. N., Chesters, G., and Harris, R. F.: Chemical and Physical Stability of Microbially Stabilized Aggregates1, Soil Sci. Soc. Am. J., 35, 283-286, https://doi.org/10.2136/sssaj1971.03615995003500020030x, 1971.

Bastida, F., Luis Moreno, J., Hernández, T., and García, C.: Microbiological degradation index of soils in a semiarid climate, Soil Biol. Biochem., 38, 3463-3473, https://doi.org/10.1016/j.soilbio.2006.06.001, 2006.

Becerra-Absalón, I., Muñoz-Martín, M. Á., Montejano, G., and Mateo, P.: Differences in the Cyanobacterial Community Composition of Biocrusts From the Drylands of Central Mexico. Are There Endemic Species?, Front. Microbiol., 10, 937, https://doi.org/10.3389/fmicb.2019.00937, 2019.

Belnap, J.: Biological soil crusts in deserts: a short review of their role in soil fertility, stabilization, and water relations, Algol. Stud., 109, 113-126, https://doi.org/10.1127/18641318/2003/0109-0113, 2003.

Belnap, J.: The potential roles of biological soil crusts in dryland hydrologic cycles, Hydrol. Process., 20, 3159-3178, https://doi.org/10.1002/hyp.6325, 2006.

Belnap, J.: CRUSTS/Biological?, in: Reference Module in Earth Systems and Environmental Sciences, Elsevier, https://doi.org/10.1016/B978-0-12-409548-9.05131-9, 2013.

Belnap, J. and Gillette, D. A.: Vulnerability of desert biological soil crusts to wind erosion: the influences of crust development, soil texture, and disturbance, J. Arid Environ., 39, 133-142, https://doi.org/10.1006/jare.1998.0388, 1998.

Belnap, J. and Lange, O. L. (Eds.): Biological soil crusts: structure, function, and management, Springer, New York, 2001.

Belnap, J., Phillips, S. L., Witwicki, D. L., and Miller, M. E.: Visually assessing the level of development and soil surface stability of cyanobacterially dominated biological soil crusts, J. Arid Environ., 72, 1257-1264, https://doi.org/10.1016/j.jaridenv.2008.02.019, 2008.

Bethany, J., Giraldo-Silva, A., Nelson, C., Barger, N. N., and Garcia-Pichel, F.: Optimizing the production of nursery-based biological soil crusts for restoration of arid land soils, Appl. Environ. Microbiol., 85, 15, https://doi.org/10.1128/AEM.00735-19, 2019.

Bever, A. D., Ndakidemi, P., and Laubscher, C.: Effects of different combinations of Hoagland's solution and Azolla filiculoides on growth and development of Beta vulgaris subsp. cycla "Fordhook Giant” grown in hydroponic cultures, Int. J. Phys. Sci., 7, 52815287, https://doi.org/10.5897/IJPS12.320, 2012.

Bowker, M. A.: Biological soil crust rehabilitation in theory and practice: an underexploited opportunity, Restor. Ecol., 15, 1323, 2007. 
Bowker, M. A., Belnap, J., Davidson, D. W., and Phillips, S. L.: Evidence for micronutrient limitation of biological soil crusts: importance to arid-lands restoration, Ecol. Appl., 15, 1941-1951, https://doi.org/10.1890/04-1959, 2005.

Brinda, J. C., Stark, L. R., Clark, T. A., and Greenwood, J. L.: Embryos of a moss can be hardened to desiccation tolerance: effects of rate of drying on the timeline of recovery and dehardening in Aloina ambigua (Pottiaceae), Ann. Bot.,, 117, 153-163, 2016.

Bu, C., Zhang, K., Zhang, C., and Wu, S.: Key Factors Influencing Rapid Development of Potentially DuneStabilizing Moss-Dominated Crusts, PLOS One, 10, e0134447, https://doi.org/10.1371/journal.pone.0134447, 2015.

Bu, C., Li, R., Wang, C., and Bowker, M. A.: Successful field cultivation of moss biocrusts on disturbed soil surfaces in the short term, Plant Soil, 429, 227-240, https://doi.org/10.1007/s11104017-3453-0, 2018.

Buttars, S. M., Clair, L. L. S., Johansen, J. R., Sray, J. C., Payne, M. C., Webb, B. L., Terry, R. E., Pendleton, B. K., and Warren, S. D.: Pelletized cyanobacterial soil amendments: Laboratory testing for survival, escapability, and Nitrogen fixation, Arid Soil Res. Rehabil., 12, 165-178, https://doi.org/10.1080/15324989809381506, 1998.

Cantón, Y., Román, J. R., Chamizo, S., Rodríguez-Caballero, E., and Moro, M. J.: Dynamics of organic carbon losses by water erosion after biocrust removal, J. Hydrol. Hydromech., 62, 258268, https://doi.org/10.2478/johh-2014-0033, 2014.

Chamizo, S., Cantón, Y., Miralles, I., and Domingo, F.: Biological soil crust development affects physicochemical characteristics of soil surface in semiarid ecosystems, Soil Biol. Biochem., 49, 96105, https://doi.org/10.1016/j.soilbio.2012.02.017, 2012.

Chamizo, S., Cantón, Y., Rodríguez-Caballero, E., and Domingo, F.: Biocrusts positively affect the soil water balance in semiarid ecosystems, Ecohydrology, 9, 1208-1221, https://doi.org/10.1002/eco.1719, 2016.

Chamizo, S., Mugnai, G., Rossi, F., Certini, G., and De Philippis, R.: Cyanobacteria Inoculation Improves Soil Stability and Fertility on Different Textured Soils: Gaining Insights for Applicability in Soil Restoration, Front. Environ. Sci., 6, 49, https://doi.org/10.3389/fenvs.2018.00049, 2018.

Chamizo, S., Adessi, A., Mugnai, G., Simiani, A., and De Philippis, R.: Soil Type and Cyanobacteria Species Influence the Macromolecular and Chemical Characteristics of the Polysaccharidic Matrix in Induced Biocrusts, Microb. Ecol., 78, 482493, https://doi.org/10.1007/s00248-018-1305-y, 2019.

Chandler, D. G., Day, N., Madsen, M. D., and Belnap, J.: Amendments fail to hasten biocrust recovery or soil stability at a disturbed dryland sandy site, Restor. Ecol., 27, 289-297, https://doi.org/10.1111/rec.12870, 2019.

Chen, L., Xie, Z., Hu, C., Li, D., Wang, G., and Liu, Y.: Manmade desert algal crusts as affected by environmental factors in Inner Mongolia, China, J. Arid Environ., 67, 521-527, https://doi.org/10.1016/j.jaridenv.2006.02.018, 2006.

Chen, L., Deng, S., De Philippis, R., Tian, W., Wu, H., and Wang, J.: UV-B resistance as a criterion for the selection of desert microalgae to be utilized for inoculating desert soils, J. Appl. Phycol., 25, 1009-1015, 2013.

Chen, L., Rossi, F., Deng, S., Liu, Y., Wang, G., Adessi, A., and De Philippis, R.: Macromolecular and chemical features of the excreted extracellular polysaccharides in induced biologi- cal soil crusts of different ages, Soil Biol. Biochem., 78, 1-9, https://doi.org/10.1016/j.soilbio.2014.07.004, 2014.

Chiquoine, L. P., Abella, S. R., and Bowker, M. A.: Rapidly restoring biological soil crusts and ecosystem functions in a severely disturbed desert ecosystem, Ecol. Appl., 26, 1260-1272, https://doi.org/10.1002/15-0973, 2016.

Colica, G., Li, H., Rossi, F., Li, D., Liu, Y., and De Philippis, R.: Microbial secreted exopolysaccharides affect the hydrological behavior of induced biological soil crusts in desert sandy soils, Soil Biol. Biochem., 68, 62-70, https://doi.org/10.1016/j.soilbio.2013.09.017, 2014.

Condon, L. A. and Pyke, D. A.: Filling the interspace-restoring arid land mosses: source populations, organic matter, and overwintering govern success, Ecol. Evol., 6, 7623-7632, https://doi.org/10.1002/ece3.2448, 2016.

Danin, A. and Ganor, E.: Trapping of airborne dust by mosses in the Negev Desert, Israel, Earth Surf. Proc. Land., 16, 153-162, 1991.

Deb, S., Rout, J., Sengupta, M., and Chakraborty, B.: Biochemical profile and antimicrobial activity of a cyanobacterium, $S c y$ tonema tolypothrichoides isolated from acidic rice field soil of Cachar district (Assam), India, Int. J. Life Sci. Pharma Res., 5, L21-L31, 2015.

de Mulé, M. C. Z., de Caire, G. Z., de Cano, M. S., Palma, R. M., and Colombo, K.: Effect of cyanobacterial inoculation and fertilizers on rice seedlings and postharvest soil structure, Commun. Soil Sci. Plant Anal., 30, 97-107, https://doi.org/10.1080/00103629909370187, 1999.

Doherty, K. D., Grover, H. S., Bowker, M. A., Durham, R. A., Antoninka, A. J., and Ramsey, P. W.: Producing moss-colonized burlap fabric in a fog chamber for restoration of biocrust, Ecol. Eng., 158, 106019, https://doi.org/10.1016/j.ecoleng.2020.106019, 2020.

Duckett, J. G., Burch, J., Fletcher, P. W., Matcham, H. W., Read, D. J., Russell, A. J., and Pressel, S.: In vitro cultivation of bryophytes: a review of practicalities, problems, progress and promise, J. Bryol., 26, 3-20, 2004.

Evans, R. D. and Johansen, J. R.: Microbiotic Crusts and Ecosystem Processes, Crit. Rev. Plant Sci., 18, 183-225, https://doi.org/10.1080/07352689991309199, 1999.

Faist, A. M., Antoninka, A. J., Belnap, J., Bowker, M. A., Duniway, M. C., Garcia-Pichel, F., Nelson, C., Reed, S. C., GiraldoSilva, A., Velasco-Ayuso, S., and Barger, N. N.: Inoculation and habitat amelioration efforts in biological soil crust recovery vary by desert and soil texture, Restor. Ecol., 28, S96-S105, https://doi.org/10.1111/rec.13087, 2020.

Falchini, L., Sparvoli, E., and Tomaselli, L.: Effect of Nostoc (Cyanobacteria) inoculation on the structure and stability of clay soils, Biol. Fertil. Soils, 23, 346-352, https://doi.org/10.1007/BF00335965, 1996.

Fattahi, S. M., Soroush, A., Huang, N., Zhang, J., Jodari Abbasi, S., and Yu, Y.: Laboratory study on biophysicochemical improvement of desert sand, Catena, 190, 104531, https://doi.org/10.1016/j.catena.2020.104531, 2020.

Fick, S. E., Barger, N. N., and Duniway, M. C.: Hydrological function of rapidly induced biocrusts, Ecohydrology, 12, e2089, https://doi.org/10.1002/eco.2089, 2019.

Fick, S. E., Day, N., Duniway, M. C., Hoy-Skubik, S., and Barger, N. N.: Microsite enhancements for soil stabilization and rapid 
biocrust colonization in degraded drylands, Restor. Ecol., 28, S139-S149, https://doi.org/10.1111/rec.13071, 2020.

Gao, G.-L., Ding, G.-D., Wu, B., Zhang, Y.-Q., Qin, S.-G., Zhao, Y.-Y., Bao, Y.-F., Liu, Y.-D., Wan, L., and Deng, J.F.: Fractal Scaling of Particle Size Distribution and Relationships with Topsoil Properties Affected by Biological Soil Crusts, edited by: Esteban, F. J., PLoS ONE, 9, e88559, https://doi.org/10.1371/journal.pone.0088559, 2014.

Garcia-Pichel, F. and Castenholz, R. W.: Characterization and biological implications of scytonemin, a cyanobacterial sheath pigment 1, J. Phycol., 27, 395-409, 1991.

Garcia-Pichel, F. and Castenholz, R. W.: Occurrence of UVabsorbing, mycosporine-like compounds among cyanobacterial isolates and an estimate of their screening capacity, Appl. Environ. Microbiol., 59, 163-169, 1993.

Giraldo-Silva, A., Nelson, C., Barger, N. N., and GarciaPichel, F.: Nursing biocrusts: isolation, cultivation, and fitness test of indigenous cyanobacteria, Restor. Ecol., 27, 793-803, https://doi.org/10.1111/rec.12920, 2019.

Gold, W. G. and Bliss, L. C.: Water Limitations and Plant Community Development in a Polar Desert, Ecology, 76, 1558-1568, 1995.

Greenwood, J. L., Stark, L. R., and Chiquoine, L. P.: Effects of rate of drying, life history phase, and ecotype on the ability of the moss Bryum argenteum to survive desiccation events and the influence on conservation and selection of material for restoration, Front. Ecol. Evol., 7, 388, https://doi.org/10.3389/fevo.2019.00388, 2019.

Grover, H. S., Bowker, M. A., Fulé, P. Z., Doherty, K. D., Sieg, C. H., and Antoninka, A. J.: Post-wildfire moss colonisation and soil functional enhancement in forests of the southwestern USA, Int. J. Wildland Fire, 29, 530-540, 2020.

Guedes, A. C., Katkam, N. G., Varela, J., and Malcata, F. X.: Photobioreactors for cyanobacterial culturing, in Cyanobacteria, John Wiley \& Sons, Ltd., 270-292, 2013.

Guo, Y., Zhao, Y., and Downing, A. J.: Effect of storage time on the physiological characteristics and vegetative regeneration of desiccation-tolerant mosses on the Loess Plateau, China, Restor. Ecol., 28, S203-S211, 2020.

Hamdi, Y. A.: Application of nitrogen-fixing systems in soil improvement and management, Food \& Agriculture Org., Rome, Italy, 1982.

He, X., He, K. S., and Hyvönen, J.: Will bryophytes survive in a warming world?, Perspect. Plant Ecol. Evol. Syst., 19, 49-60, 2016.

Hilty, J. H., Eldridge, D. J., Rosentreter, R., Wiclow-Howard, M. C., and Pellant, M.: Recovery of biological soil crusts following wildfire in Idaho, Rangel. Ecol. Manage. J. Range Manag. Arch., 57, 89-96, 2004.

Hu, C., Liu, Y., Song, L., and Zhang, D.: Effect of desert soil algae on the stabilization of fine sands, J. Appl. Phycol., 14, 281-292, 2002.

Hu, C., Zhang, D., Huang, Z., and Liu, Y.: The vertical microdistribution of cyanobacteria and green algae within desert crusts and the development of the algal crusts, Plant Soil, 257, 97-111, https://doi.org/10.1023/A:1026253307432, 2003.

Hu, C., Gao, K., and Whitton, B. A.: Semi-arid Regions and Deserts, in: Ecology of Cyanobacteria II, edited by: Whitton, B. A., Springer Netherlands, Dordrecht, 345-369, 2012.
Lan, S., Zhang, Q., Wu, L., Liu, Y., Zhang, D., and Hu, C.: Artificially Accelerating the Reversal of Desertification: Cyanobacterial Inoculation Facilitates the Succession of Vegetation Communities, Environ. Sci. Technol., 48, 307-315, https://doi.org/10.1021/es403785j, 2014.

Lan, S., Wu, L., Zhang, D., and Hu, C.: Effects of light and temperature on open cultivation of desert cyanobacterium Microcoleus vaginatus, Bioresour. Technol., 182, 144-150, https://doi.org/10.1016/j.biortech.2015.02.002, 2015.

Li, H., Colica, G., Wu, P., Li, D., Rossi, F., De Philippis, R., and Liu, Y.: Shifting Species Interaction in Soil Microbial Community and Its Influence on Ecosystem Functions Modulating, Microb. Ecol., 65, 700-708, https://doi.org/10.1007/s00248-012-0171-2, 2013.

Li, H., Li, R., Rossi, F., Li, D., De Philippis, R., Hu, C., and Liu, Y.: Differentiation of microbial activity and functional diversity between various biocrust elements in a heterogeneous crustal community, Catena, 147, 138-145, https://doi.org/10.1016/j.catena.2016.07.008, 2016.

Li, X.-R., He, M.-Z., Zerbe, S., Li, X.-J., and Liu, L.-C.: Microgeomorphology determines community structure of biological soil crusts at small scales, Earth Surf. Proc. Land., 35, 932-940, https://doi.org/10.1002/esp.1963, 2010.

Liffman, K. and Paterson, D. A.: Comparing the energy efficiency of different high rate algal raceway pond designs using computational fluid dynamics, Chem. Eng. Res. Des., 91, 221-226, https://doi.org/10.1016/j.cherd.2012.08.007, 2013.

Liu, Y. D.: Integrated Management of Desertification by "AlgaeGrass-Shrub (Tree)" Technology and Regional Sustainable Development, Science Press, Beijing, China, ISBN 978-7-03030246-5, 2013.

Maestre, F. T., Martín, N., Díez, B., López-Poma, R., Santos, F., Luque, I., and Cortina, J.: Watering, Fertilization, and Slurry Inoculation Promote Recovery of Biological Crust Function in Degraded Soils, Microb. Ecol., 52, 365-377, https://doi.org/10.1007/s00248-006-9017-0, 2006.

Maestre, F. T., Bowker, M. A., Cantón, Y., Castillo-Monroy, A. P., Cortina, J., Escolar, C., Escudero, A., Lázaro, R., and Martínez, I.: Ecology and functional roles of biological soil crusts in semiarid ecosystems of Spain, J. Arid Environ., 75, 1282-1291, https://doi.org/10.1016/j.jaridenv.2010.12.008, 2011.

Mager, D. M. and Thomas, A. D.: Carbohydrates in cyanobacterial soil crusts as a source of carbon in the southwest Kalahari, Botswana, Soil Biol. Biochem., 42, 313-318, https://doi.org/10.1016/j.soilbio.2009.11.009, 2010.

Maier, S., Tamm, A., Wu, D., Caesar, J., Grube, M., and Weber, B.: Photoautotrophic organisms control microbial abundance, diversity, and physiology in different types of biological soil crusts, ISME J., 12, 1032-1046, https://doi.org/10.1038/s41396018-0062-8, 2018.

Maqubela, M. P., Mnkeni, P. N., Muchaonyerwa, P., D’Acqui, L. P., and Pardo, M. T.: Effects of cyanobacteria strains selected for their bioconditioning and biofertilization potential on maize dry matter and soil nitrogen status in a South African soil, Soil Sci. Plant Nutr., 56, 552-559, 2010.

Mazor, G., Kidron, G. J., Vonshak, A., and Abeliovich, A.: The role of cyanobacterial exopolysaccharides in structuring desert microbial crusts, FEMS Microbiol. Ecol., 21, 121-130, https://doi.org/10.1111/j.1574-6941.1996.tb00339.x, 1996. 
Michel, P., Payton, I. J., Lee, W. G., and During, H. J.: Impact of disturbance on above-ground water storage capacity of bryophytes in New Zealand indigenous tussock grassland ecosystems, NZ J. Ecol., 37, 114-126, 2013.

Miralles, I., Domingo, F., Cantón, Y., Trasar-Cepeda, C., Leirós, M. C., and Gil-Sotres, F.: Hydrolase enzyme activities in a successional gradient of biological soil crusts in arid and semiarid zones, Soil Biol. Biochem., 53, 124-132, https://doi.org/10.1016/j.soilbio.2012.05.016, 2012.

Mitri, G., Nasrallah, G., Gebrael, K., Bou Nassar, M., Abou Dagher, M., Nader, M., Masri, N., and Choueiter, D.: Assessing land degradation and identifying potential sustainable land management practices at the subnational level in Lebanon, Environ. Monit. Assess., 191, 567, https://doi.org/10.1007/s10661-0197739-y, 2019.

Mugnai, G., Rossi, F., Felde, V. J. M. N. L., Colesie, C., Büdel, B., Peth, S., Kaplan, A., and De Philippis, R.: Development of the polysaccharidic matrix in biocrusts induced by a cyanobacterium inoculated in sand microcosms, Biol. Fertil. Soils, 54, $27-$ 40, https://doi.org/10.1007/s00374-017-1234-9, 2018a.

Mugnai, G., Rossi, F., Felde, V. J. M. N. L., Colesie, C., Büdel, B., Peth, S., Kaplan, A., and De Philippis, R.: The potential of the cyanobacterium Leptolyngbya ohadii as inoculum for stabilizing bare sandy substrates, Soil Biol. Biochem., 127, 318-328, https://doi.org/10.1016/j.soilbio.2018.08.007, 2018b.

Mugnai, G., Rossi, F., Chamizo, S., Adessi, A., and De Philippis, R.: The role of grain size and inoculum amount on biocrust formation by Leptolyngbya ohadii, Catena, 184, 104248, https://doi.org/10.1016/j.catena.2019.104248, 2020.

Nelson, C., Giraldo-Silva, A., and Garcia-Pichel, F.: A fogirrigated soil substrate system unifies and optimizes cyanobacterial biocrust inoculum production. Appl. Environ. Microbiol., 86, e00624-20, https://doi.org/10.1128/AEM.00624-20, 2020.

Park, C.-H., Li, X., Jia, R. L., and Hur, J.-S.: Effects of Superabsorbent Polymer on Cyanobacterial Biological Soil Crust Formation in Laboratory, Arid Land Res. Manage., 29, 55-71, https://doi.org/10.1080/15324982.2014.928835, 2015.

Park, C.-H., Li, X. R., Zhao, Y., Jia, R. L., and Hur, J.S.: Rapid development of cyanobacterial crust in the field for combating desertification, PLoS ONE, 12, e0179903, https://doi.org/10.1371/journal.pone.0179903, 2017.

Pisa, S., Werner, O., Vanderpoorten, A., Magdy, M., and Ros, R. M.: Elevational patterns of genetic variation in the cosmopolitan moss Bryum argenteum (Bryaceae), Am. J. Bot., 100, 20002008, 2013.

Pointing, S. B. and Belnap, J.: Microbial colonization and controls in dryland systems, Nat. Rev. Microbiol., 10, 551-562, https://doi.org/10.1038/nrmicro2831, 2012.

Román, J. R., Roncero-Ramos, B., Chamizo, S., RodríguezCaballero, E., and Cantón, Y.: Restoring soil functions by means of cyanobacteria inoculation: Importance of soil conditions and species selection, Land Degrad. Dev., 29, 3184-3193, https://doi.org/10.1002/ldr.3064, 2018.

Román, J. R., Chilton, A. M., Cantón, Y., and Muñoz-Rojas, M.: Assessing the viability of cyanobacteria pellets for application in arid land restoration, J. Environ. Manage., 270, 110795, https://doi.org/10.1016/j.jenvman.2020.110795, 2020a.

Román, J. R., Chamizo, S., Roncero-Ramos, B., Adessi, A., De Philippis, R., and Cantón, Y.: Overcoming field barriers to re- store dryland soils by cyanobacteria inoculation, Soil Till. Res., 207, 104799, https://doi.org/10.1016/j.still.2020.104799, 2020b.

Roncero-Ramos, B., Román, J. R., Gómez-Serrano, C., Cantón, Y., and Acién, F. G.: Production of a biocrust-cyanobacteria strain (Nostoc commune) for large-scale restoration of dryland soils, J. Appl. Phycol., 31, 2217-2230, https://doi.org/10.1007/s10811019-1749-6, 2019a.

Roncero-Ramos, B., Román, J. R., Rodríguez-Caballero, E., Chamizo, S., Águila-Carricondo, P., Mateo, P., and Cantón, Y.: Assessing the influence of soil abiotic and biotic factors on Nostoc commune inoculation success, Plant Soil, 444, 57-70, https://doi.org/10.1007/s11104-019-04239-y, 2019b.

Rossi, F., Olguín, E. J., Diels, L., and De Philippis, R.: Microbial fixation of $\mathrm{CO}_{2}$ in water bodies and in drylands to combat climate change, soil loss and desertification, New Biotechnol., 32, 109-120, https://doi.org/10.1016/j.nbt.2013.12.002, 2015.

Rossi, F., Li, H., Liu, Y., and De Philippis, R.: Cyanobacterial inoculation (cyanobacterisation): Perspectives for the development of a standardized multifunctional technology for soil fertilization and desertification reversal, Earth-Sci. Rev., 171, 28-43, https://doi.org/10.1016/j.earscirev.2017.05.006, 2017.

Rossi, F., Mugnai, G., and De Philippis, R.: Complex role of the polymeric matrix in biological soil crusts, Plant Soil, 429, 1934, https://doi.org/10.1007/s11104-017-3441-4, 2018.

Schroeter, B., Green, T. G., Kulle, D., Pannewitz, S., Schlensog, M., and Sancho, L. G.: The moss Bryum argenteum var. muticum Brid. is well adapted to cope with high light in continental Antarctica, Antarct. Sci., 24, 281-291, 2012.

Sears, J. T.: Production and application of an aircraft spreadable, cyanobacterial based biological soil crust inoculant for soil fertilization, soil stabilization and atmospheric $\mathrm{CO}_{2}$ drawdown and sequestration, Google Patents, available at:http://www.google. com/patents/USH2271 (last access: 1 September 2015), 2012.

Sears, J. T. and Prithiviraj, B.: Seeding of Large Areas with Biological Soil Crust Starter Culture Formulations: Using an Aircraft Disbursable Granulate to Increase Stability, Fertility and $\mathrm{CO}_{2}$ Sequestration on a Landscape Scale, in: 2012 IEEE Green Technologies Conference, Tulsa, OK, USA, 1-3, 2012.

Singh, H.: Desiccation and radiation stress tolerance in cyanobacteria, J. Basic Microbiol., 58, 813-826, 2018.

Singh, R. N.: Role of blue-green algae in N-economy of Indian agriculture, Indian Council of Agricultural Research, New Delhi, 1961.

Slate, M. L., Durham, R. A., and Pearson, D. E.: Strategies for restoring the structure and function of lichenmoss biocrust communities, Restor. Ecol., 28, S160-S167, https://doi.org/10.1111/rec.12996, 2020.

Smith, S. D., Monson, R. K., and Anderson, J. E.: Poikilohydric plants, in: Physiological ecology of North American desert plants, Springer, Berlin, Heidelberg, 191-198, 1997.

Stark, L. R., Nichols, L., McLetchie, D. N., Smith, S. D., and Zundel, C.: Age and sex-specific rates of leaf regeneration in the Mojave Desert moss Syntrichia caninervis, Am. J. Bot., 91, 19, https://doi.org/10.3732/ajb.91.1.1, 2004.

Stark, L. R., Brinda, J. C., and McLetchie, D. N.: Effects of increased summer precipitation and $\mathrm{N}$ deposition on Mojave Desert populations of the biological crust moss Syntrichia caninervis, J. Arid Environ., 75, 457-463, 2011. 
Sveinbjörnsson, B. and Oechel, W. C.: The effect of temperature preconditioning on the temperature sensitivity of net $\mathrm{CO}_{2}$ flux in geographically diverse populations of the moss Polytrichum commune, Ecology, 64, 1100-1108, 1983.

Tamaru, Y., Takani, Y., Yoshida, T., and Sakamoto, T.: Crucial Role of Extracellular Polysaccharides in Desiccation and Freezing Tolerance in the Terrestrial Cyanobacterium Nostoc commune, Appl. Environ. Microbiol., 71, 7327-7333, https://doi.org/10.1128/AEM.71.11.7327-7333.2005, 2005.

Tang, D., Shi, S., Li, D., Hu, C., and Liu, Y.: Physiological and biochemical responses of Scytonema javanicum (cyanobacterium) to salt stress, J. Arid Environ., 71, 312-320, https://doi.org/10.1016/j.jaridenv.2007.05.004, 2007.

van der Heijden, M. G. A., Bardgett, R. D., and van Straalen, N. M.: The unseen majority: soil microbes as drivers of plant diversity and productivity in terrestrial ecosystems, Ecol. Lett., 11, 296310, https://doi.org/10.1111/j.1461-0248.2007.01139.x, 2008.

Velasco Ayuso, S., Giraldo Silva, A., Nelson, C., Barger, N. N., and Garcia-Pichel, F.: Microbial Nursery Production of HighQuality Biological Soil Crust Biomass for Restoration of Degraded Dryland Soils, Appl. Environ. Microbiol., 83, 1-17, https://doi.org/10.1128/AEM.02179-16, 2017.

Velasco Ayuso, S., Giraldo-Silva, A., Barger, N. N., and GarciaPichel, F.: Microbial inoculum production for biocrust restoration: testing the effects of a common substrate versus native soils on yield and community composition, Restor. Ecol., 28, S194S202, https://doi.org/10.1111/rec.13127, 2020.

Wang, W., Liu, Y., Li, D., Hu, C., and Rao, B.: Feasibility of cyanobacterial inoculation for biological soil crusts formation in desert area, Soil Biol. Biochem., 41, 926-929, https://doi.org/10.1016/j.soilbio.2008.07.001, 2009.

Wilpiszeski, R. L., Aufrecht, J. A., Retterer, S. T., Sullivan, M. B., Graham, D. E., Pierce, E. M., Zablocki, O. D., Palumbo, A. V., and Elias, D. A.: Soil Aggregate Microbial Communities: Towards Understanding Microbiome Interactions at Biologically Relevant Scales, Appl. Environ. Microbiol., 85, e0032419, https://doi.org/10.1128/AEM.00324-19, 2019.

Wu, Y., Rao, B., Wu, P., Liu, Y., Li, G., and Li, D.: Development of artificially induced biological soil crusts in fields and their effects on top soil, Plant Soil, 370, 115-124, https://doi.org/10.1007/s11104-013-1611-6, 2013.

Xiao, B. and Veste, M.: Moss-dominated biocrusts increase soil microbial abundance and community diversity and improve soil fertility in semiarid climates on the Loess Plateau of China, Appl. Soil Ecol., 117-118, 165-177, https://doi.org/10.1016/j.apsoil.2017.05.005, 2017.

Xiao, B., Wang, Q., Zhao, Y., and Shao, M.: Artificial culture of biological soil crusts and its effects on overland flow and infiltration under simulated rainfall, Appl. Soil Ecol., 48, 11-17, https://doi.org/10.1016/j.apsoil.2011.02.006, 2011.
Xiao, B., Ma, S., and Hu, K.: Moss biocrusts regulate surface soil thermal properties and generate buffering effects on soil temperature dynamics in dryland ecosystem, Geoderma, 351, 9-24, 2019.

Xu, S., Yin, C., He, M., and Wang, Y.: A Technology for Rapid Reconstruction of Moss-Dominated Soil Crusts, Environ. Eng. Sci., 25, 1129-1138, https://doi.org/10.1089/ees.2006.0272, 2008.

Yang, Y., Zhang, L., Chen, X., Wang, W., Bu, C., Li, Y., and Zhou, H.: Effects of chemical substances on the rapid cultivation of moss crusts in a phytotron from the Loess Plateau, China, Int. J. Phytoremed., 21, 268-278, 2019.

Yang, Y. Z.: Experimental study on wind erosion control of artificial cultivation biocrusts in the photovoltaic power plant construction slash in Mu Us Sandland, China, Graduate student of the Chinese Academy of Sciences, Research Center of Soil and Water Conservation and Ecological Environment, Chinese Academy of Sciences and Ministry of Education, Yangling, China, 2016.

Young, K. E., Bowker, M. A., Reed, S. C., Duniway, M. C., and Belnap, J.: Temporal and abiotic fluctuations may be preventing successful rehabilitation of soil-stabilizing biocrust communities, Ecol. Appl., 29, e01908, https://doi.org/10.1002/eap.1908, 2019.

Zaady, E., Ben-David, E. A., Sher, Y., Tzirkin, R., and Nejidat, A.: Inferring biological soil crust successional stage using combined PLFA, DGGE, physical and biophysiological analyses, Soil Biol. Biochem., 42, 842-849, https://doi.org/10.1016/j.soilbio.2010.02.002, 2010.

Zhao, J., Zheng, Y., Zhang, B., Chen, Y., and Zhang, Y.: Progress in the study of algae and mosses in biological soil crusts, Front. Biol. China, 4, 143-150, https://doi.org/10.1007/s11515-0080104-0, 2009.

Zhao, Y., Zhu, Q., Li, P., Zhao, L., Wang, L., Zheng, X., and Ma, H.: Effects of artificially cultivated biological soil crusts on soil nutrients and biological activities in the Loess Plateau, J. Arid Land, 6, 742-752, https://doi.org/10.1007/s40333-014-0032-6, 2014.

Zhao, Y., Bowker, M. A., Zhang, Y., and Zaady, E.: Enhanced Recovery of Biological Soil Crusts After Disturbance, in Biological Soil Crusts: An Organizing Principle in Drylands, edited by: Weber, B., Büdel, B., and Belnap, J., Springer International Publishing, Cham, 499-523, 2016.

Zhou, X., Zhao, Y., Belnap, J., Zhang, B., Bu, C., and Zhang, Y.: Practices of biological soil crust rehabilitation in China: experiences and challenges, Restor. Ecol., 28, S45-S55, https://doi.org/10.1111/rec.13148, 2020. 